\title{
La obligación tributaria ¿una obligación moral?
}

\author{
Por Francisco GOMEZ CAMACHO
}

\begin{abstract}
No se puede habler de obligación en conclencla sin conocer previarnente los valores que definen cada contexto polftico y socio-económico.
\end{abstract}

La obligación moral tributaria ha sido siempre uno de los temas clásicos de la moral católica. Si prescindimos de la problemática planteada por la teoría de las leyes meramente penales, podemos decir sin temor a equivocarnos que la obligación en conciencia a pagar los tributos constituyó el núcleo básico de la moral impositiva tradicional. Esta obligación se fundamentaba con razones de derecho natural y de ley divina positiva (1).

La misma doctrina tradicional afirmó siempre que dicha obligación moral en conciencia se mantenía a nivel de la "teoría y como principio" (2); jamás se propuso el moralista como tarea propia el hacer descender las afirmaciones teóricas y en principio al campo conflictivo de la realidad empírica concreta. Esta era una misión que, por razones gnoseológicas y sistemáticas, se dejaba en manos del "técnico".

Todo lo que en este artículo se dice tiene como finalidad exclusiva el análisis de algunos problemas que plantea el salto del nivel teórico de los principios morales al terreno comprometido de !a realidad fiscal. Al delimitar así el tema, pretendo un doble objetivo: evitar que las ideas aquí expuestas puedan interpretarse legítimamente como un intento explícito de negar la doctrina tradicional; pero, al mismo tiempo y no menos importante, subrayar que existe

(1) Gonzalo Higuera, S. 1.: Tributos y moral en los siglos XVI y XVVU, Pontificia Universitas Comillensis, Madrid, 1963, págs. 32-44.

(2) Gonzalo Higuera, S. I., op. cit., pág. 31. 
toda una gama de problemas que afectan directamente a la ciencla moral y que ésta, por considerar ese salto "zona desmilitarizada", había olvidado, en mi opinión, imprudentemente. Es la zona divisoria de dominios cientificos, en la que el moralista, a la vez que se negaba a entrar, concedía plena inmunidad al técnico. La imagen que el moralista tenía del técnico como persona en su actividad "neutral" le justificaba su actitud, una actitud que, como veremos, es imposible mantener hoy. Queda, pues, claro que me moveré en esa zona comprometida y peligrosa que se sitúa "entre dos fuegos": el del moralista y el del técnico.

A una posición peligrosa no se asciende si no existen motivos fuertes para ello. ¿Qué motivos explican mi posición en este artículo? Es evidente que la gestión de la Hacienda Pública ha evolucionado en los últimos cincuenta años, de forma que, en la actualidad, obedece a unos principios que distan mucho de ser los principios clásicos presupuestarios. Nuevas circunstancias socioeconómicas y políticas aconsejaron a la autoridad civil la revisión de la doctrina tradicional y la elaboración de nuevos principios. ¿Cómo han afectado estos cambios a la doctrina moral de la obligación tributaria? Cualquiera que consulte los libros de moral (3), aun los más recientes, observará con sorpresa que los moralistas siguen repitiendo lo que creen fueron principios defendidos por los doctores escolásticos y que, curiosamente, los problemas que nuevas circunstancias históricas plantearon a la Hacienda Pública están ausentes de sus libros.

¿Es posible que la misma doctrina moral siga conservando todo su sentido orientador después de convulsiones sociales como las que ha vivido Occidente en los últimos siglos? ¿Existen motivos para esperar fundadamente que la misma doctrina moral tributaria conserve su fuerza en el nuevo contexto socio-económico y político que caracteriza a la sociedad actual? Si su validez sigue intacta, ¿qué clase de doctrina es ésta a la que ni los cambios históricos más radicales afecta? La respuesta a estas preguntas, lejos de ser un ejercicio puramente académico, constituye una de las exigencias más urgentes para la teología moral. ¿Cómo extrañarnos de que la realidad de la vida concreta de un pueblo no responda a las exigencias morales de una doctrina, si esa misma doctrina se formula al resguardo de todo posible cambio de la vida real? Si una misma doctrina es aplicable a diversos contextos históricos, jamás esa doctrina explicará el paso de un contexto a otro, y. recíprocamente, si diversos contextos sociales son subsumibles bajo la misma doctrina moral, jamás aquéllos explicitarán el alcance significativo de ésta. Si éste es el caso de la doctrina moral tributaria, el trabajo que se ofrece al moralista consistirá en repensar dicha doctrina moral de forma que se salve coherentemente

(3) Puede consultarse el libro de B. Häring: La ley de Cristo, Herder, Bar. celona, 1965. 
el salto existente entre principios teóricos abstractos y el contexto social concreto al que han de aplicarse esos principlos.

No son exclusivamente razones históricas y metódológicas las que justifican una revisión de la doctrina tradicional; existen, además, razones eclesiales: "Las transformaciones económicas, socia" les, políticas y culturales de nuestra época, que plantean nuevos interrogantes a cuantos desean ser fieles al Evangelio en la sociedad de hoy, obligan a la Iglesia a reflexionar sobre las relaciones entre la fe cristiana y los problemas de orden temporal " (4). No es sólo la sociedad la que ha cambiado, también la Iglesia se piensa a sí misma en la actualidad de forma diferente. De una concepción de la Iglesia como sociedad pertecta hemos pasado a la Iglesia comunidad o pueblo de Dios. Después de este cambio, ¿cómo debe entenderse la obligación moral tributaria, como exigencia nacida de una verdadera comunidad cristiana o como imposición de una determinada sociedad civil? ¿Qué consecuencias se derivan para la obligación moral tributaria del nuevo contexto de relaciones Iglesia-Estado?

Las preguntas son numerosas y no de fácil respuesta. Espero que estas páginas contribuyan a una comprensión más exacta del alcance de las mismas.

\section{1.-LA OBLIGACION MORAL TRIBUTARIA}

Bajo la expresión "obligación moral tributaria" se oculta todo un conjunto de problemas que, si bien deben separarse con fines expositivos y de investigación, no es posible dejar de relacionarlos cuando de la decisión moral se trata. La moral, como ciencia práctica que es (5), aspira a configurar (no sólo a denunciar) la conducta humana. Pero es evidente que la conducta humana no puede orientarse en un sentido o en otro sólo en virtud de consideraciones unilaterales o parciales que prescinden de numerosos aspectos esenciales a la realidad en la que nace. La decisión humana debe ser racional, y nada más irracional que la decisión nacida de la lgnorancia o del conocimiento incompleto. La naturaleza de un problema no se conoce-en la medida de que esto es posible, si es que lo es en alguna medida-sino cuando se conocen todos aquellos elementos que entran a formar parte de ese problema. Imponer una obligación en conciencia, sin antes tomar a peso todos los condicionantes previos y consecuencias futuras derivadas de un contexto determinado, lejos de ser exigencia de la moral, sería imposición de la ignorancia o la inconsciencia. La obligación moral, por pertenecer a la esfera de lo religioso, no

(4) "La Iglesia y la comunidad política", Declaración de la Conferencia Episcopal Española, enero 1973, núm. 1 .

(5) B. Häring, op. cit, tomo 1 . 


\section{F. GOMEZ CAMACHO}

puede utilizarse inconscientemente ni a la ligera $y$, mucho menos, como instrumento de poder personal o político.

No es posible, por tanto, hablar de ubligación moral tributarian, si no es después de haber analizado con el mayor rigor posible cuál es el contexto político, socio-económico y religioso en el que nace o puede nacer dicha obligación. La "obligación moral tributarian no es un problema exclusivamente religioso (moral), pertenece también a la esfera de lo político y socio-económico; pero tampoco puede reducirse, en cuanto obligación moral, al campo de lo político. Ni lo político es autosuficiente para imponer una obligación moral, ni lo religioso puede atribuirse fuerza moral para imponer una obligación tributaria: la "obligación moral tribu* taria" nace o se destruye en función de un contexto socio-histórico del que forman parte integrante elementos religiosos, políticos y económicos conjuntamente. Por esta razón, un estudio que pres. cinda de uno cualquiera de estos tres aspectos no pasará de ser un estudio parcial, incompleto $y$, en consecuencia, incapacitado para poder concluir con legitimidad y fundamentación cientifica la obligación moral tributaria. Ninguna obligación en conciencia puede justificarse en base a un estudio incompleto.

La segunda parte de este artículo recoge en breve resumen cuáles fueron algunas de las circunstancias económicas y políticas que especificaron el contexto social de los últimos siglos, su influjo en la ciencia de la Hacienda Pública y el significado de la obll. gación tributaria en esos contextos.

\section{2.-EVOLUGION DEL CONTEXTO HISTORICO}

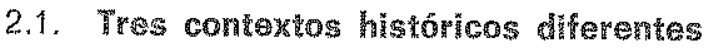

La estructura de una sociedad en un lugar y momento dados, así como la ideología que su legislación incorpora, vienen condicionadas en gran medida por la manera cómo dicha sociedad afronta sus necesidades materiales. Si esto es así cuando de la sociedad en general se trata, to es con especial intensidad cuando nos reducimos al ámbito de las relaciones fiscales y los derechos y obligaciones que explicitan esas relaciones. La ideología política de la Hacienda Pública, así como su sistematización en forma de un derecho fiscal determinado, es inintelligible sl se prescinde del orden económico en el que se inserta la actividad del Sector Público.

Esta es una realidad en la que no tendriamos que insistir si no fuera por el olvido en que la doctrina moral de la obligación tributaria la ha tenido hasta el momento presente. Quizá pocos puntos de la moral tributaria tradicional más sorprendentes que éste: de- 
rivándose el contenido de la Hacienda Pública del enfoque general que de la actividad económica se tenga, ¿cómo es posible que los moralistas se refieran a las funciones del Sector Público y sus "derechos" sin preguntarse previamente por los valores que sirven esas funciones dentro del sistema económico?

Otra constatación previa y no menos importante es la que nos advierte de una clara evolución histórica del orden económico dentro del cual se han de entender los derechos y obligaciones fiscales. El orden económico medieval fue distinto del vigente en el siglo XIX, que, a su vez, evolucionó hacia el orden que actualmente vivimos.

En la sociedad feudal, cuando las relaciones individuo-sociedad se tejían conforme a la tradición de una sociedad estratificada en clases sociales, el orden económico en que se sustentaba la obligación tributaria estaba lejos de ser el orden individualista del siglo XIX. La economía del laissezfaire aún no había alcanzado la madurez y las responsabilidades sociales de los individuos no podían delegarse en la "mano invisible" del liberalismo. Dentro del contexto socio-económico de la Edad Media, la legislación fiscal obedecía a unos fines y se materializaba en unos instrumentos que, por los valores sociales a que respondían, nada tenían que ver con los que habrían de establecerse en la etapa liberal. ¿Quién puede hoy ignorar que las relaciones individuo-sociedad sufrieron un cambio radical con ocasión de la Revolución Francesa? ¿Cómo desconocer que el individualismo económico y social que acompañó a la Revolución Industrial destronó de la sociedad todo intento consciente de solidaridad social? La sociedad en que una "mano invisible" cuidaba del bien común, dejando a los individuos en libertad para buscar sus propios intereses, representó la antítesis de la sociedad medieval, en la que los individuos, más que por su propia valía personal, se estimaban por la clase social a que pertenecian.

La sociedad feudal desapareció, y un nuevo orden económico sustituyó al antiguo. La filosofía liberal desplazó a la medieval, y el régimen económico del XIX necesitó de un nuevo ordenamiento político y fiscal. El sistema tributario no escapó a esta transformación social; para el ideario liberal, las actividades estatales que los ingresos públicos debían financiar quedaron reducidas a tres: actividades orientadas a mantener el orden exterior (defensa nacional); actividades necesarias para mantener el orden interno (justicia y policía); actividades económicas que, por no ajustarse a las motivaciones de la empresa privada-máximo lucro--, se reservaban al Estado. Como después veremos, cuando este cambio de la Hacienda Pública cristaliza en Derecho Presupuestario, se formulan con toda precisión y sin dar lugar a interpretaciones am. biguas, todo un conjunto de principios contables, económicos y políticos definidores de los valores implícitos en la nueva orienta- 
ción. En relación con el nuevo orden económico, el moralista debería recordar que "las normas de moralidad económica vinieron desde entonces a cifrarse en un único precepto: acatamiento a las leyes del mercado; si el individuo mantenía la mira puesta en sus proplos intereses económicos, se daba por descontado que tra. bajaba en pro de toda la sociedad" (5).

Desde finales del siglo XVIII hasta la primera guerra mundial estuvo en vigor el orden económico y la ideología político-económica sobre la que se asentaba la Hacienda Pública clásica. A partir de la primera guerra mundial la situación cambió radicalmente. La guerra habia demostrado la capacidad organizadora del Estado, y resultaba ingenuo seguir defendiendo la incapacidad del Estado para dirigir y organizar la vida económica. Unos años después, durante la depresión de los años treinta, Occidente conoció dolorosamente la incapacidad de las leyes del mercado y de la "mano invisible" de A. Smith para promover el bien de la sociedad. Se hacía necesario un cambio. Si la ideología político-económica del liberalismo capitalista había sido refutada, aún faltaba otra ideolo. gía más concorde con las aspiraciones sociales y los hechos recientemente vividos que pudiera sustituir a la antigua. Nadie como lord Keynes contribuyó a este relevo de ideologías: su Teoría General ofrecía la base económico-teórica para la ideología neocapitalista.

También en esta ocasión, el cambio en la concepción de la actividad económica supuso una transformación en los principios rectores de la Hacienda Pública. Cuál fue el sentido de este cambio lo comprenderemos mejor una vez conozcamos los principios vigentes en el contexto liberal anterior.

\subsection{Valores deflnidores de los diversos contextos}

Acabamos de señalar la existencia de tres contextos socioeconómicos netamente diferenciados $(6)$. La interpretación de esos contextos debería constituir la base previa (no exclusiva) para toda valoración moral de la obligación tributaria. El contexto de la sociedad feudal respondía a unos valores que distaban mucho de ser los valores del liberalismo; a su vez, la sociedad liberal es. tructuró su contexto socio-económico y político de acuerdo con una concepción del hombre y la sociedad distinta de la actual. ¿Cómo negar que en cada uno de esos contextos la obligación moral tributaria estaría apoyando valores diferentes? ¿Cómo podría el moralista hablar de obligación en conciencia sin conocer

(5) B. Häring, op. cit., tomo I.

(6) Estos "contextos" no deben interpretarse en sentido estrictamente histórico, sino analítico. No supone una concepción de la evolución histórica como sucesión de contextos ideales perfectamente delimitados, su finalidad es puramente analítica $e$ instrumental. 
previamente los valores que definían cada contexto? La moral no puede elaborarse de espaldas a esos valores y delegar en los "técnicos" la obligación de instrumentalizar unos principios abstractos; los mismos técnicos nos recuerdan que uel contenido esencial de la teoría general del impuesto deriva de las exigencias que el mundo de valores de la sociedad plantea al sistema tributario en su conjunto. Es decir, ¿cómo debería ordenarse, en su conjunto, el sistema tributario, dada su profesión de fe en un mundo deter. minado de valores?" Incluso la teoría especial del impuesto "debe elaborarse a un nivel normativo, lo que significa que, en definitiva, lo que se pretende en ella no es otra cosa que estudiar en qué sentido los diversos elementos componentes del sistema tributario afectan a cada uno de los objetivos fundamentales de la convivencian (7).

Si después de estas advertencias de los mismos "técnicos", el moralista se negase a reconocer las implicaciones que una decisión técnica tiene en el campo de lo valorativo, estaría negándose a ver la realidad y, con su conducta, daría pie a que se le aplicasen las palabras del Evangelio: "Son ciegos que guían a ciegos. Y si un ciego guía a otro ciego, los dos caerán en el hoyon (Mt., 15, 16).

¿Qué valores concretos sirve el sistema impositivo? De acuer. do con la metodología que vengo siguiendo, la respuesta a esta pregunta no puede prescindir de la referencia contextual. Esta referencia contextual sugiere una primera distinción: la actual es. tructura política del mundo nos permite polarizar los acuerdos existentes en torno a dos grandes grupos, obviando las divergencias internas menores que se perciben dentro de cada uno de ellos. En primer lugar nos encontramos con el conjunto de valores más utilizados en los países de Occidente, cuya estructura económica se configura de acuerdo con un sistema de economía de mercado. En segundo lugar, los valores defendidos por los paises con un sistema económico de dirección central.

Enunciados brevemente, los valores a los que trata de acomodarse el sistema fiscal occidental son los siguientes: suficiencia y flexibilidad económicas, eficacia económica, justicia y equidad. Los sistemas insertos en economías centralizadas aspiran a la colectivización, industrialización, flexibilidad económica y equidad. entendiendo esta última en el sentido de que "la renta y la riqueza deberian distribuirse de acuerdo con las necesidades más bien que en relación con las aportaciones económicas de los sujetos, a fin de conseguir una disminución de las desigualdades en la distribución de la riqueza y de la renta" (8).

La distinción anterior obedece a formas distintas de organización económica (economía de mercado, economía planificada).

(7) Enrique Fuentes Quintana: Hacienda Pública (Teoría General de los Ingresos Públicos), curso 1966-67, págs. 50-51.

(8) Enrique Fuentes Quintana, op. cit., pág. 51. 


\section{F. GOMEZ CAMACHO}

Pero acabamos de ver en el epígrate anterior que también la economía de mercado del siglo XIX respondía a un contexto histórico diferente del contexto actual. Los principios normativos que configuraban la actividad económica y fiscal de estos contextos tampoco puede ignorarlos el moralista. Prescindiendo de los principios contables, el resto se agrupa en dos direcciones: principios económicos y principios políticos, todos ellos expresión de los valores socialmente aceptados.

\subsection{El contexto liberal}

Recordemos los principios económicos. En primer lugar, el dogma del mal necesario: el gasto público es preciso, pero constituye un mal que debe limitarse e incluso reducirse lo más posible. Convicción arraigada en los economistas y políticos del siglo pasado era la que veía en el gasto público un gasto improductivo, y en el Estado, una institución incapaz de dirigir la economía nacional. En segundo lugar, debería evitarse todo posible efecto pernicioso de los impuestos que financiaban el gasto público. Pero ¿qué se entendía por "efectos perniciosos"? Para los economistas y políticos clásicos, el impuesto neutral era el que carecía de esos efectos. Se entendía que un impuesto era neutral si no modificaba lo más mínimo la situación económica relativa de los contribuyentes, es decir, si respetaba la distribución de la renta y la riqueza derivada de las leyes del mercado y no buscaba una explícita corrección de esa distribución. Junto con los principios ante. riores, la regla de oro de la Hacienda Pública; se insistía en que el presupuesto estuviera equilibrado, imponiendo así al Sector Público una actuación paralela y no compensatoria de la actividad privada. Finalmente, la Deuda Pública sólo podría emitirse para in. versiones autoliquidables (rentables).

Acompañando a estos principlos económicos, los principios políticos. El principio político básico lo constituye el principio de competencia. El presupuesto fue una exigencia política del pueblo para garantizar sus derechos sobre los programas de ingresos y gastos públicos. "La historia del derecho presupuestario casi constituye una historia de la soberanía popular y, por esto, la aprobación del documento presupuestarlo corresponde a la Cámara Baja, que, recogiendo la representación popular, votaba el contenido propio de los programas de ingresos y de gastos públicos" (9). El segundo de estos principios es el de universalidad o integridad. En este principio, nos dicen los técnicos hacendistas, "está impli" cita la desconfianza parlamentaria para con el Poder Ejecutivo. Manteniendo la regla de la universalidad, es imposible que escape

(9) Enrique Fuentes Quintana: Hacienda Pública (Presupuesto y Gasto P(xblico], curso 1966-67, pág. 88 . 
a la autorización y vigilancia del Parlamento cualquier movimiento de fondos" (10). Cumpliendo con el tercer principio político, todos los recursos y gastos de la Hacienda Pública deberían incluirse en un solo presupuesto. Se aspira con el principio de unidad presupuestaria a que el control popular se vea facilitado. Los principios de claridad, junto con los de especialidad y temporalidad, además de su finalidad contable, favorecen el control parlamentario del Ejecutivo. Por último, el presupuesto debía ser público; "es cuestión que afecta a todos los ciudadanos, es del pueblo y para el pueblo, y debe ser fiscalizado por él» (11).

Expuestos los principios económicos y políticos que regulaban la Hacienda Pública clásica, sólo nos faltaría añadir los principios contables para obtener una visión suficientemente completa de los valores que para la sociedad liberal debía respetar y cumplir la actividad económica del Sector Público. El contexto definido por estos principios "responde a una estructura política determinada (la del Estado constitucional) e intenta traducir las exigencias de ese Estado en virtud de reglas y principios políticos y contables. Sí se tiene en cuenta que esta visión liberal del mundo económico corrió pareja con la contemplación de los asuntos políticos desde la perspectiva del Estado constitucional durante el siglo XIX y comienzos del XX, se tendrá una explicación clara de por qué estas ideas presupuestarias informaron la administración del plan de la Hacienda Pública durante ese mismo espacio de tiempo" (12).

\subsection{En el contexto intervencionista.}

Según acabamos de ver, la ideología presupuestaria clásica se materializó en dos grupos de principios: los económicos, que justificaban un determinado comportamiento del grupo político frente a la actividad económica, y los políticos, que exigían una división de los poderes del Estado y una adjudicación de la elaboración del presupuesto, administración y juicio de éste a cada uno de esos poderes. Como ya indiqué, la primera guerra mundial supuso el comienzo del fin de esta ideología político económica. ¿Qué prin. cipios se impusieron a partir de entonces como explicación de los valores sociales del nuevo contexto histórico?

El alcance del cambio producido en la orientación del Sector Público se comprenderá si pensamos que el dogma clásico del mal necesario fue sustituido por el principio, no menos dogmático, del gasto público como bien necesario. El Estado deja de ser considerado unidad improductiva y pasa a ser uno de los agentes principales del sistema económico. Al mismo tiempo, la exigencia

(10) Enrique Fuentes Quintana, op. cit., pág. 88.

(11) Ibídem.

(12) lbidem, pág. 89. 
de neutralidad impositiva es sustituida por la beligerancia explícita en orden a conseguir una mejor distribución de la renta. Los problemas que la interpretación valorativa de esta beligerancia implica están lejos de aparecer resueltos. El equilibrio presupuestario deja de ser la regla de oro: el presupuesto puede estar desequilibrado si con ello contribuye a la estabilización de la demanda efectiva. Finalmente, tampoco el crecimiento de la Deuda Pública debe constituir una preocupación, si realmente contribuye a la expansión de la renta nacional, la producción y el empleo. Este cambio de los princípios económícos reflejaba sin lugar a dudas un giro completo en el enfoque de la actividad económica del Sector público. ¿Cómo afectó el cambio a los principios políticos?

La finalidad expresa de los principios políticos clásicos era la de recortar las facultades del Ejecutivo dentro del ámbito definido por el Estado constitucional de derecho. En el contexto sociopolítico que siguió a la primera guerra mundial, la búsqueda de una mayor eficacia de la acción política se ha traducido en una clara tendencia al reforzamiento de los poderes del Ejecutivo. Se instaura con ello una etapa que los tratadistas del Derecho Político han llamado "dictadura del Premier". Con este giro, el principio de compezencia, si bien no ha sido anulado, sí se ha visto suavizado; la iniciativa popular a través del Parlamento está hoy muy debilitada, siendo diferente el alcance de esa pérdida de poder popular en los diversos regímenes. También el principio de universalidad ha sido ampliamente modificado. Las excepciones a este principio son numerosas y se agrupan en dos núcleos; excepciones fundamentales (presupuesto industrial, seguridad social, fondos y cajas especiales...) y secundarias (reintegros, gastos extraordinarios). En general, así como la crisis de los principios económicos fue total, la de los principios políticos fue sólo parcial. $Y$ es que, en realidad, la ideología socio-política inspiradora de la "Teoría general de la ocupación, el interés y el dinero" no supuso un corte real con los valores sociales del liberalismo. Para Keynes, como para muchas personas en la actualidad, "los problemas de la indigencia, la pobreza y la lucha económica entre las clases y las naciones no son nada más que una confusión tremenda, una confusión transitoria e innecesaria" (12 bis), que, una vez disipada, permitiría comprender en toda su bondad y justicia la filosofía sociopolítica del sistema liberal-capitalista. No es necesario decir que, frente a la opinión keynesiana, otros historiadores y economistas ven en las crisis y los problemas socio-económicos que ocasionan una consecuencia de contradicciones sociales más profundas, cuyo alcance y significado moral es mayor que el que se deriva de una mera equivocación por ignorancia de las leyes económicas.

(12 bis) J. M. Keynes: Essays in persuasion, pág. VII, Oxford. 


\section{3.-REFLEXION DEL MORALISTA}

Conociendo ya los principios normativos que regulan la actividad del Sector Público en cada uno de los contextos socio-económicos señalados, y la actitud valorativa del hombre y la sociedad que en esos principios se explicita, estamos capacitados para comprender el alcance práctico de la obligación moral tributaria.

Un primer dato a tener en cuenta por el moralista, antes de concluir a favor o en contra de la obligación moral impositiva, es la diversidad de contextos socio-económicos existentes. Más aún, ha de reconocer que, en algunos de esos contextos, los ingresos impositivos representan sólo un capítulo marginal de los ingresos públicos. Ni a lo largo de la historia, "ni incluso en el momento actual puede afirmarse que en todas las Haciendas los ingresos por impuestos adquieren esta importancia preponderante. Para comprobar la primera afirmación basta contrastar, por ejemplo, la clasificación de los ingresos realizada por los cameralistas, en donde el impuesto aparecía en un lugar muy subordinado respecto de la preponderancia de las empresas estatales y de los dominios públicos, e incluso de las regalías. La verdad de la segunda afirmación se comprueba en cuanto nos alejamos de la Hacienda Pública occidental y comparamos lo que sucede en las Haciendas Públicas de dirección central, países en los cuales otros ingresos de la imposición tienen una importancia básica" (13)

A la luz de estos hechos, ¿qué sentido de solidaridad puede incorporar una obligación moral tributaria en un contexto en el que los impuestos constituyen sólo una mínima parte de los ingresos públicos? ¿Supone la doctrina de la obligación moral impositiva una toma de posición ante las diversas formas de financiar la actividad pública? Si la imposición no pasa de ser "la circuns" tancia actual por la que atraviesa la financiación del Sector Público" (14), ¿participa la obligación moral impositiva de ese carácter circunstancial?

\subsection{En el contexto liberal}

Supongamos que, prescindiendo de otros posibles contextos so cio-políticos, nos limitamos a estudiar las implicaciones morales de los valores que inspiran los principios liberales. El primer principio que plantea problemas a la doctrina moral tradicional es el conocido como dogma del mal necesario. Está fuera de toda duda que para los "técnicos" del siglo pasado el gasto público era un gasto improductivo, y el Estado, una institución incapaz de dirigir

(13) Enrique Fuentes Quintana (Teoría General de los Ingresos Públicos), pág. 7.

(14) Ibidem. 


\section{F. GOMEZ CAMACHO}

la economía nacional. ¿Qué sentido podría tener en este contexto hablar de una obligación moral a financiar algo que, aunque nece. sario, se juzgaba ser un mal social? Para evitar la respuesta fácil, pero errónea, aplicada al contexto que venimos estudiando, de relacionar la obligación tributaria con la obligación de solidaridad social, nos sale al encuentro el segundo principio económico: los impuestos con que el gasto público se financiaba debían ser neutrales y respetar la posición económica relativa de los individuos. ¿Qué solidaridad puede instrumentar un impuesto cuya caracterís. tica esencial es la de dejar al pobre en su pobreza y al rico en su riqueza? El recurso al "técnico" y su principio de neutralidad tam. poco nos permite descubrir la función solidaria del sistema impositivo liberal.

Quizá el moralista pensaba en la necesidad social de financiar aquellas actividades que la sociedad encomendaba al Estado. De ser ésta la fundamentación correcta de la obligación tributaria en el contexto clásico, estaríamos justificando la obligación moral por la necesidad social de contribuir a la financiación de la guerra, de la justicia y policía y, finalmente, de ciertas actividades económicas marginales. ¿Es ésta una fundamentación moralmente aceptable y sin dificultades sistemáticas?

Convendría tomar conciencia de los valores morales que subyacen a este razonamiento antes de afirmar que los tributos con que dichas actividades se financian obligan moralmente en conciencia. Pensemos -y no es un caso ausente de nuestra sociedad en los objetores de conciencia. Si una persona se niega a participar en la guerra por motivos religiosos o simplemente humanos y respetamos su actividad, ¿acaso los mismos motivos no conservan su fuerza cuando se trata, no ya de participar personalmente en la guerra o su preparación, sino de financiarla con el propio dinero? ¿Sobre quiénes recae una mayor responsabilidad moral, sobre los árabes e israelíes que luchan en Oriente Medio o sobre las grandes potencias que les suministran armas y recursos? Si hoy la Iglesia admite que pueda existir-y la respetaobjeción de conciencia ante el servicio militar, ¿no sería inconsecuente si negase la posibilidad de esa misma objeción ante leyes que regulan, más o menos directamente, la financiación de la guerra o su preparación? Supóngase que el objetor a financiar la carrera de armamentos acepta y propone que su obligación económica para con la sociedad se destine a fines sociales humanitarios, ¿puede el moralista imponerle la obligación de delegar en el Gobierno la decisión sobre el uso que se debe hacer de su contribución social?

Por otro lado, la legitimidad de la guerra es uno de esos problemas abiertos y del que lo menos que podemos decir moralmente es que no está claro que, desde una perspectiva cristiana, la guerra pueda considerarse un mal necesario. Si sobre la legitimidad de 
la guerra existen opiniones diversas y ninguna de ellas obliga en conciencia, ¿cómo puede afirmarse que existe obligación en con ciencla a financiar una actividad que directamente es bélica?

Es evidente y soy consciente de ello, que no todos los impues. tos se dedican a financiar actividades relacionadas con la guerra $y$, por tanto, el razonamiento anterior no sería aplicable a aquellos impuestos que se orientan hacia otras actividades del Sector Público. De todas formas, el moralista haría bien estudiando la proporción que, incluso en la actualidad, se dedica a Ministerios relacionados con el Ejército en sus diferentes Cuerpos.

Si del "orden exterior" pasamos al "orden nacional interno", los problemas no son más sencillos ni las obligaciones más claras. Determinadas concepciones del orden público responden con demaslada frecuencia a una insolidaridad entre los ciudadanos, semejante a la que subyace en la contraposición de la nación frente a otros pueblos. Quizá sea ésta la razón de la tesis tradicional según la cual sólo se han de obedecer las leyes justas. Cuando se estudia el orden social desde una perspectiva cristiana, convendría repensar la tesis de la maldad intrinseca del hombre y la bondad del orden establecido. Sin necesidad de caer en el extremo opuesto y admitir ingenuamente una bondad humana a ultranza, sí podemos afirmar sin lugar a dudas que, desde una visión cristiana, todo orden legalmente establecido es y será siempre imperfecto, por ser obra humana; más aún, a veces es incluso injusto. Cuando dentro del orden social nos limitamos al orden económico existente en un momento dado, no creo sea posible afirmar la existencia siempre de una "obligación moral" que imponga el someterse a dicho orden económico. La obligación tributaria es una de las muchas que se derivan de uno de los órdenes económicos posibles; ¿puede obligar en conciencia si el orden económico del que nace no obliga?

Intentemos comprender la obligación moral tributaria desde los valores implícitos en los principios politicos clásicos. ¿Cómo incide en la obligación impositiva la doctrina política de la soberanía popular? Si fuera posible que un pueblo se engañase a sí mismo practicando el fraude fiscal, ¿debería condenarse a ese pueblo por inmoral o, más modestamente, calificarle de insensato e inconsecuente con sus proplas decisiones? ¿Puede un sujeto defraudarse a sí mismo y actuar por ello mismo de forma inmoral? ¿Quién puede atribuirse poder para juzgar a toda una sociedad que admite como práctica habitual el engaño?

Los principios políticos liberales respondian a la desconfianza parlamentaria (popular) respecto del Ejecutivo. La doctrina tradicional moral parece reflejar una cierta desconfianza del Ejecutivo para con el pueblo. En el contexto socio-politico que vengo estudiando, ¿qué sentido puede tener esta desconfianza frente al pue 
blo? ¿Es posible que en una sociedad estructurada de acuerdo con las leyes vigentes en un Estado de Derecho, el Ejecutivo desconfíe de la población a la que representa? ¿Cómo habría de interpretarse la desconfianza del representante para con el representado, del administrador para con el administrado?

\subsection{En el contexto intervencionista}

Cuando se abandona el contexto socio-económico liberal y se consideran los valores a que responde el contexto definido a partir de la primera guerra mundial, el moralista no puede ignorar que los principios económicos de la Hacienda Pública clásica quedan abolidos y las tareas encomendadas al sector público, notablemente ampliadas. ¿Puede la moral respaldar esas tareas con la fuerza de una obligación en conciencia sin comprometerse por ello mismo con la interpretación económica y política de la sociedad que originó dlicho cambio? La estabilidad económica, el pleno empleo, el desarrollo..., los fines a los que en la actualidad responde la actividad del sector público, no son fines cuya interpretación valorativa aparezca evidente; diferentes grupos sociales-incluso diferentes escuelas económicas y políticas -interpretan la nueva orientación del sector público de forma contradictoria. ¿Puede el moralista aceptar acríticamente esos fines y asumirlos en su doctrina moral?

Permítaseme terminar estas reflexiones morales con el siguiente comentario de E. H. Carr: "Todo tipo de control estatal o de planificación colectiva suscita automáticamente varios problemas, y no resulta posible desentenderse de ellos apelando vagamente a la eficiencia nacional (o la solidaridad social, añadiría). Dichos problemas son: Eficiencia, ¿con qué objeto?, y planificación, ¿para qué? Estas preguntas tienen repercusiones prácticas agudas, ya que las respuestas determinan el curso de nuestra política. El régimen capitalista del siglo XIX ha venido a transformarse, a través de un proceso de evolución histórica, en un sistema donde la intervención y el planeamiento estatal se vuelven imperativos. Lo que es todavía incierto y se presta a muchas controversias es determinar la finalidad para la que el Estado se arroga la función de intervenir y de planificar: (15). ¿Puede el moralista entrar en esta problemática sin participar en la controversia?

\section{4 -CONCLUSION}

Estos son algunos de los problemas que se plantean ante el deseo sincero de comprender el significado real de unas normas morales formuladas a nivel "teórico y en principio". Es relativa-

(15) E. H. Carr: La nueva sociedad, F. C. E. México, 1969, pág. 55. 
mente fácil concluir la existencia posíble de una obligación moral tributaria, pero análogamente a como no todos los seres e hipótesis posibles son reales, tampoco toda posible obligación moral es real. Naturalmente, ahí radica la dificultad del problema moral: ¿Cómo se pasa de una obligación posible a la obligación real? ¿Cómo saber si una obligación hipotética es, además, real? Mien. tras la moral no evolucione en su metodología y acepte la necesidad de formular proposiciones significativas dentro de un contexto determinado, el individuo-que no puede prescindir del contexto socio-económico en que se encuentra inmerso-se verá en la necesidad de "lanzar la escala" desde la fortaleza que es la moral tradicional y descender él solo al campo de batalla donde se plantean los problemas concretos. Es esta una operación que, como he venido insistiendo, nada tiene de "neutral", y si el moralista renuncia a ella, se expone a que el "técnico" arroje la escala en campo contrario.

Finalmente, quiero referirme a una posible interpretación errónea de todo lo anterior. ¿Significaría mi razonamiento que los ciudadanos están dispensados de contribuir al bien común de la sociedad? ¿Podrían los individuos sentirse liberados de su obligación para con la sociedad sobre la base de las ideas aquí expuestas? Nada más lejos de mi intención y de la fuerza de los argumentos correctamente entendidos. La única conclusión válida a la que es lícito llegar en virtud de estas páginas sería aquella que señalase, en primer lugar que no es legítimo establecer la existencia de una obligación concreta y real si no se explicita el contexto para el que esa obligación se defiende, y en segundo lugar, que cuando se trata de la "obligación moral tributaria", el contexto significativo lo configuran, esencialmente, elementos políticos, socie-económicos y religiosos que el moralista no puede legítimamente olvidar. 